\title{
COR COMO SÍMBOLO DE CLASSIFICAÇÃO SOCIAL $(*)$.
}

VERENA MARTINEZ-ALIER

"Os Europeus e seus descententes nascidos na América não podem resistir por muito tempo ao calor escaldante dos trópicos. A morte prematura de tantos jovens que vêm à América somente para cavar suas sepulturas oferece prova suficiente deste lamentavel fato. Os negros africanos ou nascidos na América são os únicos que estão aptos a suportar a constante fadiga sob este clima abrasador que é semelhante ao deles, somente eles, pela espes-

- sura de sua pele e por sua tez acostumada às rgiões equinociais e aos rigores de todas as estações" (Honorato Bernard de Chateausalins, El Vademecum de los Hacendados Cubanos. Havana, 1854).

"... o proletariado branco trata a classe de cor numa situação de igualdade". (Declaração de um funcionário do governo local feito por volta de 1850).

O ponto básico que desejo foca'izar aqui é o de que preconceito racial e discriminação são fatos determinados não física, mas socialmente. Peculiaridades físicas são, em si mesmas, neutras. Não implicam, como tais, em desigualdade. Isto é verdade tanto para diferenças raciais como sexuais. O que faz o citado apologicta da escravidão é apenas exagerar diferenças físicas para fins sociais. Em outros termos, "raça" não é mais que um símbolo útil, usado para enfatizar e legitimar outras divisões na estrutura social.

Cuba e Porto Rico foram as últimas colônias espanholas na América. E Cuba foi, juntamente com o Brasil, o último reduto da

(*). - Tradução do inglês, devidamente autorizada, por Maria C:istina Godoy Oliveira e José Luiz dos Santos (Nota da Redação). 
escravidão. Em razão do declínio econômico das Indias Ocidentais Britânicas e da revolução haitiana, em fins do século XVIII, Cuba experimentou um surto econômico que a transformou em poucas décadas, no primeiro produtor de açúcar para o mercado mundial. A emergência de uma economia de plantation teve dois efeitos interdependentes: levou a uma demanda sempre crescente de trabalho escravo e, consequentemente à introdução maciça dos mesmos, e a uma simultânea e perceptível deterioração das relações raciais.

\section{COR REAL E COR LEGAL.}

Idealmente, a sociedade cubana do século XIX dividia-se em dois grandes grupos (1), o de origem européia e o de origem africana, tendo por critério de distinção a aparência física. Mas a implementação do fenótipo como princípio de clasificação social tinha-se tornado, até essa época, um tanto complexa. Havia-se dado um alto grau de miscigenação, que apagara significativamente as fronteiras visíveis dos grupos raciais. Este processo de crescente indefinição dos atributos raciais derivou um momentum adicional da poderosa e sempre presente aspiração de parte da população de cor a desfazer-se de seu status social inferior aparentmente determinado pela raça, desfazendo-se de seus atributos físicos típicos.

Um decreto real de 1788 revela uma aguda percepção dos problemas de segregar a população segundo linhas raciais bem como de suas causas:

"... a dificuldade em implementar (a) Pragmática Real sobre casamento em vista das várias castas de povo... e da mistura

(1). - Já em fins do século XVIII uma legislação reduzindo a liberdade de casamento havia sido aprovada pela Espanha. E em 1805, em resposta a pressões das colônias, foi promulgada uma lei tornando a licença governamental um requisito formal para os brancos que desejassem intercasar com pessoas de cor. Os termos desta lei eram equívocos. Não ficava inteiramente claro se esta estipulação se aplicava apenas à nobreza ou a todos os brancos independentes de seus status sociais. Com efeito, a interpretação e a implementação da lei variaram através do século, em resposta direta às condições de mudança socio-econômica e política da llha. José Maria Zamora y Coronado, Bibliografia de Legislação Ultramarina em forma de Dicionário Alfabético. Madrid, 1845. Real Cédula de 15 de outubro de 1805 acerca de los matrimonios que personas de conocida nobleza pretendan contraer com las de castas de negros y mulatos; Joaquín Rodriguez San Pedro, Legislacion ultramarina, concordada $y$ anotada. Madrid, 1868 p. 531, Nota de Rodapé. O volume do material empregado neste artigo foi tomado aos processos surgidos desta legislação, mantidos no Archivo Nacional de Cuba em Havana. Estes requerimentos por uma licença para intercasamento com pessoas de cor contém tanto as razões dos requerentes brancos para desejarem tal casamento, como relatórios de funcionários, sacerdotes e vizinhos respeitáveis acerca de sua adequação. 
fatal de europeus com os nativos e os negros... resulta o fato de que os que provêm dessas misturas, a fim de ocultar seus defeitos tentam registrar seus batismos nos livros para espanhóis, e apagam por meios repreensiveis a informação sobre sua origem, justificando depois facilmente e com a ajuda de testemunhas, que eles são considerados brancos ... o que causa aflição àqueles vassalos que são verdadeiramente brancos e não podem evitar casamentos entre suas famílias e os que sendo mestiços, pretendem o contrário" (2).

Seguramente, a diferença entre ser "considerado branco" e ser "verdadeiramente branco" não era a de cor física. Também em Cuba no século XIX, a aparência física tornou-se bastante enganosa com relação à origem racial de uma pessoa. Frequentemente era difícil, senão impossível, perceber qualquer distinção física entre uma pessoa de origem espanhola e uma de origem parcialmente africana. Pichardo, enı seu Dicionário provincial casi razonado de voces y frases cubcinas, publicado pela primeira vez em 1836 , dá a seguinte definição da palavra trigueño:

"A pessoa de cor ligeiramente mais escura, ou semelhante à do trigo, da mesma forma que a pessoa de cor mais clara, leitosa, com um tom rosado é chamada branca. Num contexto racial, a palavra branco é usada mesmo se a pessoa é trigueña, a fim de diferenciá-la do negro ou mulato, embora haja alguns destes últimos que são mais brancos do que muito dos da raça branca" (3).

(2). - Richard Konetzke (ed.), Colección de documentos para la historia dela formación social de hispanoamérica, 1493-1810. Madrid, 1953-1962. A partir de agora (DFS). III: 2, p. 625. (os itálicos são meus).

(3). - Esteban Pichardo, Pichardo Novíssimo o Diccionario Provincial casi razonado de voces y frases cubanas. O seguinte caso exemplifica bem o problema da classificação social pela aparência física, numa situação de miscegenação: "Tanto quanto ele pode ver, a resolução deste caso depende de que Nicolas, pai do suplicante se apresente, a quem V. M. parece desejar ver pessoalmente, para deduzir de seu semblante se ele é pardo ou não. Materialmente falando, cor é um acidente, pois, como mostra a experiência, muitos indivíduos da mais distinta e clara origem assemelham-se e poderiam ser tomados por pardos e, reciprocamente, muitos daqueles cujos pais de um ou de outro lado vieram no bojo de um navio da costa da África parecem, por suas características, semblantes e pele branca, ser de origem branca. Assim, embora Nicolas Almanza, pai do referente, tenha cor avermelhada, isto não significa que a avó do referente, a parda Ana de Ayala, deixe de ser sua mãe, nascida, batizada e reputada como parda na aldei de Guanabacoa... Mesmo que seu pai tivesse uma pele branca e rosada o cabelo crespo e áspero e o nariz largo e grosso, aliados a outras circunstâncias, fazem dele um verdadeiro pardo. Archivo General de Indias (a partir de agora (A. G. I.), Capitanía General de la Isla de Cuba. Leg. 1696. 
Os processos sobre casamento inter-racial; nos quais se baseou esta análise, contem numerosas alusões à avaliação e ao uso da aparência física como um critério de classificação social, e suas complexidades. Assim, um vizinho, em seu relato sobre um casal misto sugere a possível ausência de diferenças físicas entre pessoas de origem racial diversa:

"ela é uma parda criola de Santiago de Cuba que pode passar por branca fora deste país e que é inclusive de uma cor melhor que seu pretendente (que é de origem espanhola)" (4).

Este não é, certamente, um caso isolado. De uma outra jovem disseram que

"embora ela diga que é mulata, ela é de cor clara" (5),

e ainda de outra que,

"embora a noiva dele seja tida como pertencente à classe parda sua aparência o contradiz" (6).

Finalmente, outra jovem é descrita como sendo

"daquelas pardas que podem nesta aldeia e mesmo em outros lugares passar por branca" (7),

e a opinião de um funcionário sobre outra parda é de que

"ela não tem má aparência, (sendo) de cor branca" (8).

As dificuldades envolvidas na estratificação social segundo linhas raciais em uma sociedade já miscigenada emergem particularmente claras no caso de crianças abandonadas. Por decreto real, os abandonados eram de "sangue puro". A imposição desta lei nas possessões ultramarinas colocou muitos problemas

(4). - Archivo Nacional de Cuba, Gobierno Civil (a partir de agora A. N. C. Gob. Sup. Civ.) Leg. 922/32149.

(5). - A. N. C. Gob. Civ. Leg. 893/30306.

(6). - A. N. C. Gob. Civ. Leg. 895/30522.

(7). - A. N. C. Gob. Civ. Leg. 924/32259.

(8). - A. N. C. Gob. Civ. Leg. 923/3229; também Leg. 924/32284. 
"devidos à grande variedade de castas" (10) pois esta prerrogativa baseava-se, segundo as palavras de um funcionário de 1786, somente numa "ficção ou suposição privilegiada" (11).

Consequentemente a solicitação de um abandonado do Orfanato de Havana para que lhe fosse concedido o privilégio de nobreza foi rejeitada porque

"sabe-se que ele é um abandonado e, portanto na realidade de origem incerta" (12).

Quando defrontadas com solicitações desta natureza, as autoridades, para estabelecer a "realidade", recorriam à cor da pele. Em 1772 , o Conselho das Indias sugeriu que as autoridades eclesiásticas das possessões ultramarinas fossem instruidas a

"não dispensar ou ordenar nenhum abandonado que por sua aparência e sinais bem conhecidos, denote ser mulato ou de quaisquer outras castas igualmente indecorosas" (13).

Além dišo a decisão sobre a petição de um homem branco por consentimento real para seu casamento com uma abandonada foi colocada na dependência da cor da noiva,

"indicando se ela era filha de brancos" (14).

Significativo nos dois casos precedentes é o fato de que cor ou aparência física são concebidos não como atributos conclusivos em si proprios, mas como meros "signos" externos de uma condiçãa mais profunda. A qualidade simbólica da aparência física neste contexto é fortemente percebida pela jovem branca que rejeitou seu pretendente após já ter concordado em se casar com ele, porque

"sendo considerado de cor, como se diz, ela desistiu de seu propósito de esposá-lo, pois se acalentara esta idéia foi pelo fato de ele ter-lhe assegurado, repetidamente, de que era tão branco quanto ela mesma, ocultando esta circunstância... (ele estava) tentando enganá-la, sob o pretexto de ser branco".
(9). - CDFS. III: 2, p. 612.
(10). - CDFS, III: 1, p. 392.
(11). - CDFS. III: 2. p. 613 .
(12). - CDFS, III: 2, p. 614. (os itálicos são meus).
(13). - CDFS, III: 1, p. 392.
(14). - CDFS, III: 2, p. 787. 
Ele deve ter sido de tez muito clara para ter sido capaz de manter oculto o jogo, até ser descoberto que seu certificado de batismo estava registrado no livro dos pardos (15). Consequentemente, sua cor não poderia ser a verdadeira razão para as objeções da moça. Foi sua cor legal a decisiva neste caso (16). Em outro exemplo, o jovem que deseja se casar com uma parda insiste em que

"como sua mãe é branca, ele foi batizado como branco, mas infelizmente... sua mãe se uniu a um homem de cor, e desta união resultou o suplicante, cuja aparência física, cabelo crespo (afasado) e cor escura provam que pertence à classe de cor".

O funcionário encarregado do caso, no entanto, rejeita a petição do jovem sob a alegação de que

"confuso e cego pela idéia de que a lei o separa do objeto de seu amor, ele não hesita em se apresentar a S. M., desdenhando os direitos e privilégios que possui como homem branco, ao extremo de não desejar sê-lo, se deste modo pudesse alcançar seu objetivo. O certificado de batismo apresentado (por eles) é um documento irrepreensivel, certifica que êle é branco e como tal deve ser considerado" (17).

Novamente, a cor legal prevalece sobre a aparência física. Mas isto não significa que a aparência física não tinha qualquer relevância. A situação inversa bem pode ocorrer, a aparência física prevalecendo sobre a cor legal. Isto é ilustrạdo por um relatório, afirmando que

"eles dizem que são do interior, sua origem é desconhecida aqui, mas de acordo com sua aparência, ele parece mulato e é considerado aqui, por muitos, como tal" (18).

(15). - A. N. C. Gob. Sup. Civ. Leg. 924/32292.

(16). - Ibidem.

(17). - A. N. C. Gob. Sup. Civ. Leg. 934/32748.

(18) . - A. N. C. Gob. Sup. Civ. Leg. 889/29969. Em outro cáso ele é um abandonado e, assim registrado como "aparentemente branco". Por isso, as autoridades concluem: "desde que a certidão de batismo do requerente não estabelece positivamente que ele é branco; se os seres desafortunados que vivem da caridade pública e protegidos por sua bondade tem uma origem que será eternamente desconhecida com razão mais que suficiente esta origem pode ser atribuida tanto à mais alta como à mais baixa fonte, resultado da união de dois seres de outra raça que a branca, ou descendentes delà em grau mais ou menos remoto. Se isto é assim, Antonio Nazario Valdes não pode ser encarado como branco, mesmo se parece sê-lo, e menos ainda se houver a mais leve indicação da mistura clandestina das raças, e se ele próprio afirma que é e deseja ser considerado pardo". 
E Bacardi, em suas Crônicas de Santiago de Cuba conta sobre um homem chamado Vidal cuja brancura foi questionada por outro homem. Ele levou o caso a julgamento e venceu, o que lhe mereceu a seguinte sátira (19):

\author{
Señor Vidal, yo bien sé \\ que es usted blanco en la Audiencia \\ pero en Dios y en mi conciencia, \\ medio mulato es usté.
}

A cor legal era, portanto, uma maneira alternativa de determinar o status racial de uma pessoa, quando sua aparência física não era um guia inequívoco. Além de oferecer informação sobre o próprio status de um indivíduo, o registro de batismo indicava também o status racial de seus pais. Mas a cor legal não era um indicador mais válido sobre a verdadeira origem racial de uma pessoa do que a aparência física. Embora os párocos, nas possessões ultramarinas espanholas, recebessem repetidas instruções no sentido de dispender todo esforço para estabelecer acuradamente a origem racial de uma criança, antes de proceder ao seu batismo e registro (20), esta era em muitos casos uma tarefa impossíveli. Como notou um pardo requerente de uma licença de casamento, e cuja futura noiva ele acrcditava estar erradamente registrada como branca,

"tais enganos podem ser notados a cada momento" (21). E um pai comentou "que os registros de batismo de seus filhos, alguns estão no livro para brancos e outros no de pardos, de acordo com o julgamento dos diversos sacerdotes que os batizavam" (22).

Da mesma forma num relatório sobre um casal a cujo casamento se opunha um parente distante que se dizia branco, a prática do registro falso, devida aos persistentes esforços dos de origem africana para se branquearem, é novamente descrita:

“... as certidões de batismo apresentados... não tem qualquer valor por falta de consistência... além disso, neste país é muito comum alguem que de algum modo pareça branco, usar o Don... sendo também usual que, se um dos pais é branco, o ba-

(19) . - Emilio Bacardi y Moreau. Crónicas de Santiago de Cuba. Santiago de Cuba, 1925, p. 459, Vol. II.

(20). - CDFS, III: 2, p. 626.

(21). - A. N. C. Gob. Sup. Civ. Leg. 889/29978.

(22). - A. N. C. Gob. Sup. Civ. Leg. 899/30891. 
tismo seja anotado sem maiores investigaçōes, no livro para brancos... (no entanto) só posso afirmar que, segundo a opinião de pessoas eminentes, todos eles são, na verdade, mulatos, com a diferença de que alguns tentam encobrílo, enquanto outros não, mas são respeitáveis e laboriosos" (23).

Geralmente, uniōes inter-raciais eram hipergâmicas quanto à cor. E muitos pais brancos procuravam conferir suas próprias prerrogativas raciais a seus filhos mestiços, omitindo o nome da mãe, de cor, no registro. Em vários casos é feita referência a este processo particular de branqueamento:

"o pretendente não é nem branco, nem de distinção, sendo filho de uma parda conhecida e de um homem branco de baixa condição; e embora seu batismo tenha sido anotado num dos livros para espanhóis, isto se fez ocultando o nome da mãe, circunstância que indica certa malícia" (24).

Se a aparência física era então considerada como um guia insatisfatório e mesmo enganoso, recorria-se à cor legal, utilizando o registro de batismo, que fornecia informação sobre a genealogia de uma pessoa e, assim, sobre a aparência física de seus antepassados. Tanto a referência à aparência física de uma pessoa, bem como à de seus ancestrais, eram técnicas para determinar sua origem racial e social. O pai que afirma categoricamente que a noiva de seu filho

"nunca será capaz de deixar a esfera deste povo humilde, em razão de sua cor na sociedade desta aldeia, mesmo se sua pele fosse branca e seu cabelo liso" (25),

indica que seus atributos raciais não eram a causa da discriminação, mas sim o que representavam sua cor ou a de seus antepassados.

No contexto, cor significa descendência africana, mas na visão de alguns pais brancos e numerosos funcionários, era também,

"a marca da escravidão a que pertenceram os pais" (26).

A. opiniăo de que o preconceito dos brancos cubanos não é um preconceito contra pessoas de uma aparência física particular, enquan-

(23): - A. N. C. Gob. Sup. Civ. Leg. 910/31527; também Leg. $888 / 29900$

(24). - A. N. C. Gob. Sup. Civ. Leg. 898/30781.

(25) . - A. N. C. Gob. Sup. Civ. Leg. 893/30297.

(26). - A. N. C. Gob. Sup. Civ. Leg. 920/32393. 
to tal, parece ser apoiada também pelo' uso do conceito espanhol de pureza de sangue, que se desenvolveu originalmente como um resultado do esforço por uma integração nacional, através da integração religiosa, na Espanha do século XVI. Uma vez que ocorrera uma quantidade substancial de miscigenação, a pureza de sangue era certamente um critério mais rigoroso de classificação do que a aparência física. Mas aqueles que se haviam tornado fisicamente indiferenciados, poderiam ainda ser tidos como inaceitáveis, em razão da qualidade impura de seu sangue. Isto pode explicar porque o conceito de pureza de sangue, que se tornara amplamente desacreditado na Espanha, nos fins do século XVIII, experimentaria uma revivescência em Cuba.

$O$ ajustamento e o equilíbrio da ordem social em Cuba no sécuio XIX requeria a discriminação por razões funcionais. Particularmente na opinião daqueles que tinham importantes interesses investidos na escravidão, casamentos inter-raciais deveriam ser restringidos, senão proibidos abertamente, pois o "equilíbrio" da sociedade o exigia. Dollard, em sua análise sobre a fricção inter-racial nos Estados do Sul, embora enfatizando em particular o que ele denominou antagonismo "irracional", assinala também a existência de

"hostilidade racional, isto é, intelegível... nascida em defesa de um dado status ou ordem econômica" (27).

O antagonismo racial dos brancos cubanos pode em parte ser explicado nestes termos funcionais. $\mathrm{O}$ antagonismo não era dirigido contra a população de cor em razão de sua cor como tal, mas porque sua cor indicava sua origem escrava. Os escravos e seus descendentes precisavam ser segregados, no interesse do sistema escravocrata. Inicialmente houve um relacionamento direto entre atributos físicos e escravidão. Todos os escravos eram de tez escura, cabelo crespo, etc., todos os não-escravos eram de cor branca, cabelo liso, etc. Nesse momento a aparência física era realmente um critério efetivo para distinguir os escravos dos livres. Isto é, primeiro houve dois grupos ocupacionalmente distintos, e somente da subordinação necessária de um ao outro emergiu o fator da aparência física, e especialmente o da cor da pele, como pretexto para segregação. Em vista de tal interpretação "racional" do racismo cubano, surge imediatamente a questão de saber por que a população livre de cor era também frequentemente discriminada. De fato, repetidos esforços foram feitos para prevenir

(27). - John Dollard. "Hostility and Fear in Social Life". Social Forces, 17: Citado por Michael Danton. Race Relations, Londres, 1967. p. 294. 
o aumento de uma raça mestiça. Eram precisamente os mulatos livres as pessoas

$$
\text { "que precisam ser vigiadas com o maior cuidado" }
$$

presumivelmente porque, por seus atributos conflitantes, cor negra mas status livre, colocavam em risco a consistência do sistema, isso sem falar no efeito que se supunha terem os casamentos inter-raciais sobre os escravos

$$
\text { "minando sua aquiescência em seu status (28). }
$$

Por outro lado, no entanto, a legislação sobre casamento interracial parece ter sido posta em vigor com certo grau de indulgência no caso dos indivíduos de cor livres, precisamente em razão de seu maior distanciamento da "cor negra e da escravidão". Nos pareceres é evidente uma medida de compensação mútua de status. Atributos raciais poderiam, dentro de certos limites ser contrabalançados por outras qualificações.

\section{COMPENSAÇÃO MUTTUA DE STATUS.}

Como parte das formalidades em conexão com as petições de casamentos inter-raciais, deveriam ser apresentados relatórios pelas autoridades locais e pelo sacerdote local sobre a condição social e moral dos próprios pretendentes e noiva. O propósito básico destes relatórios era a avaliação dos dois candidatos em termos de correspondência de seus respectivos status sociais, econômicos e morais, em vista de seus divergentes pontos de referência étnicos. Nos pareceres sobre estes relatórios, o processo de compensação mútua de status torna-se aparente. $\mathrm{O}$ mecanismo de compensação parcial está bem descrito na seguinte decisão das autoridades:

"A constante tendência de pessoas de cor diferente a realizar casamento esteve sempre em conflito com o sentimento genuino dos habitantes destas Antilhas e das muitas possessỏes espanholas; e têm sido combatida peremptória e legalmente desde $1805 \ldots$ D. Jorge Barrera, que solicita a permissão de V. M. para esposar uma mulher de raça diferente, é como ele diz, de condição plebéia, mas seu certificado de batismo mostra que ele está livre da mistura de castas... V. M. pode chegar a uma decisão por meio dos relatórios anteriores que esta lei aconselha e indica. Esta seção entende que aqueles relatórios... não podem se referir a

(28). - A. N. C. Gob. Sup. Civ. Leg. 919/32011. 
nenhum outro aspecto senão à condição social de ambos; e, em particular, à daquele que pertence à raça branca... Se como afirma o requerente, ele é de status humilde, como simples trabalhador que é, conceder a permissão... seria certamente de importância e transcendência menores" (29).

Nestes pareceres aparecem os atributos específicos que compensavam defeitos ou equilibravam vantagens, em termos de status étnico. Dos pais de uma parda se diz que suas

"boas qualidades de honestidade e cristandade lhes proporcionaram a mais alta distinção da parte das principais famílias desta municipalidade, de modo que só lhes falta a cor, como geralmente se diz, pois todos a quem perguntei, estavam cheios de elogios para eles, tanto em vista da boa instrução e educação que $\mathbf{M}$. recebeu como quanto à probidade do mestre carpinteiro, seu pai, enquanto seu pretendente é qualificado como um "individuo sem qualquer qualificação, empregado como carregador de carvão" (30).

Neste caso, pouco se sabe da moça, além do fato de ser parda. $\mathrm{O}$ status do jovem como homem branco, no entanto, é claramente contrabaıançado por sua baixa ocupação. Apropriadamente, eles obtiveram a licença requerida; como nota um funcionário

"a diferença racial não é tão marcada, pois embora o pretendente seja branco, ele não se inclui entre aqueles desta sociedade que são de gradação elevada", (30a).

Coerente com esta avaliação diferenciada do status social é o parecer das autoridades negando a licença ao jovem cujo pai era um tenente de polícia

"cuja distinção lhe mereçe a maior estima, enquanto que a noiva era uma parda em todos os quatro lados" (31).

Como já foi afirmado, a maioria destes casamentos referidos eram hipergâmicos quanto à cor. Nos casos, entretanto, em que são hipogâmicos, parece que um cuidado ainda maior é tomado no sentido de que a mulher branca esteja em circunstâncias de completa miséria. Assim. disseram de uma mulher que

(29). - A. N. C. Gob. Sup. Civ. Leg. 932/32673.

(30) - - A. N. C. Gob. Sup. Civ. Leg. 890/30044. meus)

(30a.) - A. N. C. Gob. Sup. Civ. Leg. $923 / 32229$ (os itálicos são

(31). - A. N. C. Gob. Sup. Civ. Leg. 901/30941. 


\begin{abstract}
"ela parece ser branca, mas de condição muito humilde; sua conduta foi extremamente repreensível, em virtude da relação ilicita que vinha mantendo com o moreno Jose Joaquim por um periodo de 8 anos, causando escândalo público e perseguição pela polícia" (32).
\end{abstract}

Eles obtiveram licença para se casar. Pode-se quase dizer que o que torna uma mulher branca inelegível para casamento dentro de seu próprio grupo, torna-a elegível para casamento além da barreira racial. Reciprocamente um peso particular é atribuido à honestidade e respeitabilidade da mulher de cor que deseja se casar com um homem branco.

Outros atributos, além de sua respeitabilidade sexual, poderiam compensar o status étnico desvantajoso de uma mulher de cor. Do mesmo modo que pobreza e ocupação humilde poderiam contrabalançar o status de um homem branco, ao ponto de torná-lo elegível para casamento com uma mulher de cor, a posse de riquezas da parte da família da mulher de cor poderia, às vezes, melhorar suficientemente seu status. Dessa forma, um jovem ex-soldado, sapateiro por ocupação, desejava se casar com uma parda nascida livre, que é filha legítima de um capitão da Milícia parda e além disso, um homem rico, possuidor de propriedades de valor acima de 10.000 pesos. As autoridades convenientemente acreditam que o casamento

$$
\text { "não pode causar mal algum" (33). }
$$

Como já foi assinalado, a aparência física em termos de cor de pele, qualidade de cabelo e outros traços faciais como lábios, nariz etc. não era uma categoria absoluta, que dividisse a sociedade cubana em dois blocos monolíticos de negros e òrancos. Mesmo nos censos e nos registros paroquiais era feita uma distinção entre mulatos e negros e entre os próprios mulatos, distinguidos por variações de tom, implicando status diferencial. Assim os pareceres sobre casamento inter-racial também levavam em conta a proximidade do fenótipo do parceiro de cor ao modelo branco. Um vizinho relata sobre uma jovem:

"na classe dos de cor, ela é considerada das mais respeitáveis, em razão de sua distância da cor negra e da escravidão e em razão da boa conduta de seus ancestrais, que é o que confere distinção nas classes de cor...". Além disso, "seu pai era um hacendado

(32). - A. N. C. Gob. Sup. Civ. Leg. 889/29969.

(33). - A. N. C. Gob. Sup. Civ. Leg. 891/30118. 
e seu irmão foi condecorado por S. M.... por serviços prestados ao país, aprisionando escravos fugidos".

Estas qualidades marcantes em termos de status social e clareza de pele, mesmo sendo ela um parda, parecem tê-la tornado digna, aos olhos das autoridades, até mesmo de união com um homem branco, que

"pertence à classe de distinção, tanto em virtude de seu nascimento, como de seu status social, pois ele foi Tenente do $2^{\circ} \mathrm{Ba}$ talhão do Regimento de Infantaria de Havana" (34).

Haviam, portanto, não um, mas vários critérios de estratificação. O status social de um indivíduo dependia grandemente de sua origem, mas também de seu desempenho econômico. O prestígio social não derivava de cada fator individual separadamente, mas era determinado pela combinação de todos. Desvantagens numa escala de avaliação poderiam ser compensadas por vantagens em outra. Mas este processo de compensação operava apenas dentro de certos limites, i. e., um moreno rico dificilmente poderia aspirar a se casar a'gum dia com uma mulher branca respeitável, nem um nobre poderia sequer pensar em casamento com uma parda. Um grau de consistência era necessário entre os fatores que conferiam status. No contexto cubano eram precisamente os brancos de classe baixa e os pardos narcidos livres os de maior probabilidade para casamento. Estas uniões eram toleradas não porque houvesse uma medida de identidade étnica entre estas duas categorias, mas porque

"... o proletariado branco trata a classe de cor numa situação de completa igualdade" (35).

(34). - A. N. C. Gob. Sup. Civ. Leg. 924/32284; de outra parda foi dito, em aprovação que "tendo 16 anos de idade ela tem boa conduta e uma educação que é superior à comum na sua classe. As uniões entre as pardas e os brancos geralmente encontram, da parte dos que são desta raça privilegiada, a má vontade que é devida a costume, tradição, ansiedade e desilusōes de abandonos e frequentes dirupções familiares que elas acarretam à sociedade. Mas se devido às suas qualidades marcantes, algumas pardas deveriam ser encaradas como merecedoras de esposar um homem branco, certamente nehuma seria tão merecedora desta honra quanto Luisa Medina". A. N. C. Gob. Sup. Civ. Leg. 924/32280.

(35). - A. N. C. Gob. Sup. Civ. Leg. 924/32257. 


\section{CASAMENTO ENTRE CHINESES E BRANCOS.}

A classificação social dos chineses contribuiu para elucidar posteriormente a natureza da discriminação racial em Cuba no século XIX. Tendo início em meados de 1840 e como resultado da crescente escassez de trabalhadores, cerca de 100.000 trabalhadores chineses de Cantão, contratados, foram introduzidos em Cuba, num período de dez anos aproximadamente. Isso deu origem a agudas dificuldades classificatórias. A cor de sua pele era sem dúvida mais clara que a de muitos espanhóis. Sua cor lega1, no entanto, colocava um problema maior para as autoridades; pois como afirmou um funcionário,

"embora eles sejam considerados brancos, a opinião pública e o costume colocam-nos numa condição inferior à dos brancos" (36).

E a Junta de Agricultura, Industria y Comércio de Matanzas em 1864 , relatando sobre as maneiras de se moralizarem escravos e chineses, atribuiu o alto número de assassínios de capatazes cometidos pelos üitimos ao fato de que

"eles (os capatazes) não se convenceram ainda de que os chineses são homens livres, mas encaram-nos como se de status igual ou pior que o dos escravos negros" (37).

Além disso, um parecer do Real acuerdo de 1861, referente à petiçâa de um jovem chinês para que lhe fosse permitido esposar uma parda livre, que havia sido objetada pelo Síndico local com base em que havia

"uma tal variedade de raças povoando a Ilha",

favorece este casamento particular, mas com a cláusula de que

"não é possível estabelecer quaisquer regras gerais para futuros casos desta natureza, pois em cada caso as circunstâncias especiais... devem ser levadas em conta" (38).

(36). - A. N. C. Gob. Sup. Civ. Leg. 923-32226.

(37). - A. N. C. Consejo de Administración, Leg. 7/467.

(38). - A. N. C. Gob. Sup. Civ. Leg. 923/32226. 
E' certamente o status racial e ocupacional conflitantes que impede uma clasificação social dos chineses segundo linhas tradicionais; como notou um funcionário de Cardenas:

"Estes homens estão colocados entre as raças" (39).

Na questão do casamento acima, pode-se argumentar que o status livre da moça poderia torná-la elegível também para casamento com um branco. Em outro exemplo, no entanto, um chinês deseja esposar uma mulher parda escrava e, de fato consegue obter a licença oficial que o pároco - classificando-o como branco - julgava necessária. A petição foi preenchida em nome do chinềs por um vizinho branco, que mais uma vez assinalou que

"na realidade, para a opinião pública o citado chinês não está no mesmo nível daqueles que são propriamente brancos" (40).

Mas, em outro exemplo ainda, em que um chinês deseja carar com uma mulher branca, não são levantadas quaisquer objeções pelas autoridades, pois,

"de acordo com a certidão áe batismo apresentada, ele pertence à classe dos brancos" (41).

Até então parecia que os chineses podiam casar livremente com pessoas de qualquer cor, de uma escrava parda a uma mulher branca. Sua cor legal parecia até esse momento, altamente ambígua. Consequentemente, e em vista das numerosas dúvidas relacionadas com a classificação dos chineses para fins de batismo e casamento, o Consejo de Administración colocou o assunto em discussão em 1864. Referindo-se à Ordenanza de Colonos de 1853 e ao Reglamento de Colonos de 1854, o Conselho decidiu que os chineses deveriam ser considerados brancos. Para substanciar melhor seu parecer, o Conselho alegou que

"os índios aos quais os chineses são usualmente assemelhados foram declarados iguais aos brancos pelo Decreto Real de 12 de março de 1697, que declara os caciques e principales nobles índios (chefes e nobres) semelhantes aos hijosdalgo de Castilha, e os outros índios iguais àqueles de sangue puro de condição comum na Espanha" (42).

(39). - A. N. C. Consejo de Administración, Leg. 7/467.

(40). - A. N. C. Gob. Sup. Civ. Leg. 925/32318.

(41). - A. N. C. Gob. Sup. Civ. Leg. 925,32382.

(42). - A. N. C. Consejo de Adininistración, Leg. 7/487. 
Assim, os chineses, como os índios, eram legalmente brancos. Poder-se-ia esperar, consequentemente, que os chineses requeririam uma licença oficial para esposar mulheres de cor, segundo o decreto de 1805. Evidentemente, o Consejo de Administración estava ciente das inıp'icações legais de declarar os chineses brancos. Para enfrentar a questão do casamento, estabeleceu, contrariamente à prática usual, que os chineses estavam isentos dos requerimentos do decreto de 1805 , argumentando astutamente que não era provável que houvese nobres entre os chineses vindos a Cuba como trabalhadores contratados (43). Com relação ao registro de batismo, desde que nenhum dos pais fosse de cor, as crianças deveriam ser registradas no livro para brancos.

Não requerendo dos chineses a obtenção de uma licença de casamento, mesmo se desejassem esposar uma mulher de cor, as autoridades admitiam suas profundas dúvidas quanto ao verdadeiro status racial dos chineses. Em última análise, o parecer do Consejo de $A d$ ministración de que os chineses estavam isentos do requerimento formal de uma licença do casamente, qualquer que fosse a cor de seu cônjuge, significava ou que eles não possuiam cor legal alguma, ou que as possuiam todas. Na medida em que o status racial de uma pessoa com relação à população de cor era determinado pelo fato de ele ter ou não requerido uma licença de casamento o tenente governador de Colón estava certo ao dizer do casamento entre um chinês e uma moça branca que

"a raça chinesa é assimilada à raça negra para efeitos do Decreto Real de 15 de outubro de 1805 , e as idéias existentes quan-

(43). - Faz-se referência aqui à versão menos restritiva do decreto de 1805 sobre casamento inter-racial, segundo qual "aquelas pessoas de conhecida nobreza e conhecida pureza de sangue que tenham atingido sua maioridade e pretendam se casar com um membro das citadas castas (negros, mulatos, e outros) (devem) recorrer aos Vice-Reis, Presidentes, Audiências dos Domínios que concederão ou negarão a licença correspondente, sem a qual o casamento de pessoas de conhecida nobreza e pureza de sangue com negros, mulatos, a as outras castas não podem ser contratados, mesmo se ambos são de idade" José Maria Zamora y Coronado. Op. cit. Se tomado literalmente, poderia ser sustentado que "este decreto se aplica exclusivamente aos nobres". Em 1810, entretanto, o vice-Rei do México afirmou enfaticamente que "este decreto deveria ser interpretado para se aplicar às pessoas de conhecida nobreza ou conhecida pureza de sangue", isto é a todos os brancos quaisquer que fossem seus status sociais. Joaquin Rodrigues San Pedro, op . cit. Para uma discussão detalhada das interpretações variáveis do decreto, até sua abrogação em 1881 e - esclarecimento que isso fornece sobre as condiçôes de mudança socio-econômica e política da Ilha, ver minha tese de doutoramento. Colour, Class and Marriage in 19th Century Cuba, University of Oxford, Trinity Term 1970. 
do este decreto foi promulgado não mudaram totalmente, pois embora esta nova raça não tenha sido introduzida na Ilha nessa ocasião, e embora se acredite ser mais pura que a raça africana, não deixa de ser encarada com certa aversão pelos brancos. A grande maioria dos brancos rejeita este tipo de casamento e parece apenas justo respeitar suas opiniōes, e se se quiser suas ansiedades, fruto da organização social do país" (44).

Não necessitando de uma licença para esposar uma pessoa de cor, os chineses automaticamente se tornaram uma parte do grupo de inter-casamento de cor. Presumivelmente, as autoridades estavam cientes dos perigos implícitos na classificação ambígua dos chineses, pois a lei de que eles fossem registrados como brancos se justificava em termos de que

"eles não podem se sentir rebaixados de seu legítimo status de brancos..." (45).

A natureza problemática do trabalho escravo numa época de rápida expansão e mecanização da indústria do açúcar causou, então, certa ansiedade. A escolha do trabalhador contratado em preferência ao trabalho escravo foi certamente influenciada por esta consideração além da crescente escassez deste último. Era, portanto, uma questão de sentido político e econômico prevenir uma degradação dos chineses ao nível dos escravos, e assim minar os benefícios esperados de seu status. Nos cinco casos registrados em que chineses tentaram se casar com mulheres de cor, as autoridades centrais não levantaram objeção, à exceção de um funcionário, cuja oposição por razões funcionais foi, entretanto, rejeitada em favor da opinião do sacerdote de que

"é preferivel que eles vivam unidos pelo sagrado laço do matrimônio, do que escandalosamente em concubinato e em permanente pecado mortal",

e do argumento dos plantadores de açúcar progressistas de que

"a desvantagem não seria grande, pois, se a grande necessidade do país é atrair colonos, este objetivo não pode ser atingido de modo melhor do que autorizando uniōes legítimas" (46).

(44). - A. N. C. Gob. Sup. Civ. Leg. 930/32587.

(45) . - A. N. C. Consejo de Administración, Leg. 7/487.

(46). - A. N. C. Gob. Sup. Civ. Leg. 932/32226. 
Em princípio, os trabalhadores chineses contratados tinham duas escolhas quando do término de seu contrato: ou deixar o país com seus próprios recursos ou renovar o contrato. Mesmo que acariciassem talvez um desejo de voltar a seu próprio país, sob suas condições de trabalho eles raramente conseguiam os meios para fazê-lo. Assim, não era necessário o laço de casamento para evitar que deixassem Cuba. Presumivelmente, sentia-se que era preferível criar um proletariado misturando chineses e negros, do que misturando negros e brańcos.

\section{CONCLUSÃO.}

Por volta do século XIX, tornara-se bem estabelecido que origem africana implicava escravidão. A economia cubana, movida a trabaiho escravo, perpetuou o preconceito de cor como um ardil convencional para justificar a escravidão. O critério escolhido para classificar a população hierarquicamente era a aparência física e em particular a cor da pele, sendo esta, inicialmente, a mais consistente e também a diferença mais saliente entre os dois grupos. Enquanto estes dois grupos se fecharam inteiramente em si próprios a cor da pelc como princípio de classificação social era inequívoca e portanto muito bem sucedida. Mas com o aparecimento de um grupo de cor livre e com a progressiva miscigenação, a cor como marca distintiva do status ocupacional de uma pessoa se tornou cada vez mais equívoca e incerta. Típicos da natureza ambígua de seus status eram os negros livres e os mulatos escravos e livres. Como escreve M. Douglas

“... sempre que os limites são precários vemos que idéias de poluição vêm em seu suporte" (47).

Com efeito, no caso cubano, logo que os atributos raciais se tornaram nebulosos, recorreu-se à noção mais abstrata de "pureza de

(47). - Mary Douglas, Purity and Danger. An analysis of concepts of pollution and taboo. Londres, 1966. p. 139. Com relação à escolha de atributos físicos claramente discerníveis como critérios de classificação social, é interessante notar que, na ausência deles, os judeus da Espanha após a Reconquista foram solicitados a usar retalhos amarelos como marca distintiva, assim como os judeus na Alemanha Nazista. Embora a discriminação fosse, em ambos os casos, apoiada em termos raciais, em vista da ausência geral de diferenças raciais objetivas recorreu-se a símbolos adicionais para expressar a almejada diferença. 
sangue", que já havia sido aplicada na Espanha durante três séculos, ou a seu equivalente, a cor legal (48).

Se o status dos mulatos era com frequência a fonte de incoerência mais ainda o era o dos chineses. O mulato era o produto da mistura dos dois grupos e, instituindo o princípio da hipodescendência, segundo o qual é sempre o pai ou a mãe de status inferior que determina o da prole de uma união mista, o problema envolvido em sua classificação estava, ao menos em teoria, resolvido. Os chineses eram, entretanto, elementos estranhos, para os quais o sistema não havia estipulado cláusulas. Uma terceira catégoria especial poderia ter sido criada para dar conta dos chineses. Mas tal categoria adicional teria diminuido a clareza e a viabilidade do sistema em termos da interação entre as diferentes categorias, devido ao efeito antes integrativo que segregativo de uma categoria intermediária .

No caso dos índios, dos quais dificilmente haveria remanescentes em Cuba pelo século XIX, a política oficial revelava um grau de incoerência que, no entanto, nunca atingiu o ponto de uma admitida incapacidade do sistema em acomodar uma categoria de pessoas, como era o caso com os chineses. Os índios foram sempre considerados legalmente brancos. A cor de sua pele, no entanto, era provavelmente mais próxima a do pardo e seu status social em relação à renda variava de médio a desesperador, no caso dos poucos trabalhadores yucatecos contratados, introduzidos em Cuba no início do século.

Os chineses eram então particularmente, um problema classificatório. Pois enquanto eles aproximavam-se fisicamente dos brancos - ocupacionalmente eram, em geral como se fossem de origem africana. A cor como símbolo de uma rígida divisão de trabalho tornou-se disfuncional no casò deles.

(48). - Em contraste, Van den Berghe sustenta, em relação ao México que "paradoxalmente, a verdadeira brutalidade com que os espanhóis aniquilaram a civilização indígena... a insensibilidade com que exerceram seu droit de cuissage sobre as mulheres conquistadas. tudo contribuiu para a homogeneização cultural e genética da população... (e) levou, a longo prazo, ao sincretismo relativamente harmonioso do México moderno". Race and Racism. A Comparative Perspective. New York, 1967, p. 57. Em Cuba do século XIX, no entanto, foi precisamente quando a "homogeneização genética" avançara mais longe que a atmosfera do país foi mais segregacionista, na década de 1860 e no começo da década de 1870 . Enquanto o grau de tolerância racial pode em parte ser influenciada pelas necessidade demográficas de miscigenação, a ocorrência desta miscigenação e suas consequências genéticas não são necessàriamente produtores de tolerância. 
Assim, o contexto cubano, pode bem ser tomado como exempTo para explicar racismo como pretexto para exploração econômica, ainda mais que se pode detectar uma conexão entre circunstâncias econômicas em mudança e intensidade de discriminação. Porém a Cuba to século XIX não pode ser tratada como um isolado histórico e geográficico. A tradição cultural da Espanha, que durante três séculos esposara a "pureza de sangue" como o requisito essencial de hispanidade, deve também ser levada em consideração. Considerar a escravidão, em seus aspectos econômicos e políticos como a única causa de racismo seria por demais simples. Além disso, a persistência de uma certa consciência racial em Cuba, não apenas após a abolição da escravatura, mas ainda depois da Revolução de 1959, com sua doutrina equa'itária, levanta dúvidas sobre tal interpretação mesmo que se considere um deccompasso de tempo devido à socialização. $\mathrm{Eu}$ antes sugeriria que raça apresenta-se frequentemente como um símbolo para outras divisões - a divisão do trabalho na Cuba do século XIX, a oposição religiosa na Espanha, do século XV ao século XVIII. Em outras palavras, a divisão assimétrica da sociedade resultante de uma variedade de fatores é muitas vezes enfatizada e justificada em termos de distinções raciais.

Assinalando a natureza simbólica da raça, quero desafiar a visão de tais estudiosos das relações raciais como Hoetink e G. Freyre, que tentam explicar a diferença entre as duas variantes americanas de relações raciais em termos das diferenças determinadas culturalmente na "imagem do modelo somático" ou "miscibilidade" dos cidadãos dos respectivos poderes coloniais. Discordo também daqueles que tratam raça como um critério distinto de estratificação social e, atribuindo-lhe uma falsa permanência, equacionam relações raciais com relações de casta, ao invés de relações de classe (50). O princípio da classificação social tanto no sistema de castas quanto nas sociedades multi-raciais americanas é o mesmo, ou seja a hereditariedade. O que os distingue, no entanto, é a noção de "branqueamento" comum em Cuba, que é análoga à de "passagem" nos Estados Unidos, naccidas da ausência de consenso sobre a legitimidade do sistema nestes dois contextos. Como afirma Dumont, raça e casta são conceitos mutuamente exclusivos (51).

(49). - E. Hostink, The Two Variants of Caribbean Race Relations. Oxford, 1967, G. Freyre, The Masters and the Slaves. Nova York, 1946.

(50). - Cf. Pierre L. van den Berghe. Op. cit. Kingsley Davis. "Intermarriage in Caste-society". American Anthropologist. No 43, 1941. Classe é usada aqui em seu sentido mais amplo.

(51). - Louis Dumont, Homo Hierarchicus. Essai sur le système des castes Paris, 1966, p. 31. 